\title{
SHERLOCK HOLMES EN BRASIL: ELYSIO DE CARVALHO Y LA CIRCULACIÓN DE SABERES POLICIALES ENTRE EUROPA Y AMÉRICA DEL SUR A PRINCIPIOS DEL SIGLO XX
}

\author{
Marília Rodrigues de Oliveira \\ Pontificia Universidade Católica do Rio de Janeiro
}

\section{INTRODUCCIÓN}

G n 1912 la revista brasileña Careta publicó una serie de cróEnicas criminalísticas bajo el seudónimo de Sancho Sanches. Los artículos que se dedicaron al estudio de los punguistas, scrocs, falsificadores y gatunos de Río de Janeiro buscaban, de forma analítica, mapear los tipos de delincuentes que componían la moderna criminalidad de la ciudad. Fotografías de frente y de perfil, de los tatuajes, así como imágenes de las armas eran publicadas para ilustrar las crónicas periodísticas, construyendo todo un imaginario del submundo criminal de la capital federal brasileña. Este material que, según las crónicas, provenía de la casa de detención, da cuenta de cómo estos textos resultaban de la articulación entre los órganos de la policía y los canales de la prensa, muy probablemente por medio de individuos que circulaban entre ambos ámbitos sociales y profesionales. Un año después de esta publicación, la revista oficial del Gabinete de Identificación de la Policía de Río de Janeiro, el Boletim Policial,

Fecha de recepción: 15 de enero de 2020

Fecha de aceptación: 1 de mayo de 2020 
publicó un estudio titulado "História Natural dos Malfeitores" que era una compilación de artículos de la revista Careta, editada ahora bajo un título distinto. Con la nueva impresión, el autor que en las crónicas publicadas en la prensa adoptó el seudónimo de un espía del rey Felipe II, ${ }^{1}$ asumía que el autor de las crónicas era el propio director del Gabinete de Identificación, el escritor Elysio de Carvalho. Igual que un espía, éste circulaba en campos de actuación distintos. Hombre de letras y policía, por medio de un performance social ambiguo, el director del Gabinete de Identificación utilizaba informaciones y documentos que obtenía en los archivos de la policía como materiales para escribir crónicas en la gran prensa sobre la criminalidad moderna.

Nacido en la ciudad de Penedo, el 29 de enero de 1880, Elysio de Carvalho residió hasta 1893 en su ciudad natal, ingresando en ese año al seminario de Olinda, donde permaneció durante tres años hasta abandonar la carrera eclesiástica. Su salida definitiva del estado de Alagoas ocurrió en 1898, cuando se embarcó en un vapor en dirección a Río de Janeiro con el objetivo -frustrado- de estudiar medicina. ${ }^{2}$ Muchas fueron las estrategias del joven escritor para participar en los medios intelectuales que circulaban en la capital federal durante la primera década del siglo xx. Naturalista, decadentista y anarquista, Elysio de Carvalho circuló en movimientos políticos y artísticos hasta enrolarse en la policía de Río de Janeiro en el año de 1907. En 1914, dos años después de la publicación de la revista Careta, el director retomó su preocupación con las nuevas formas de

1 Sancho Sánchez de Muñón (1531-1600) fue profesor en la Universidad de México entre los años 1560 y 1600, al mismo tiempo que actuaba como espía del rey español Felipe II en el espacio universitario. González señala cómo el sustantivo “espía” en el siglo Xvi “tenía género femenino y designaba a personas que recibían información de carácter reservado, por motivos políticos y en favor de terceros”. Sobre la trayectoria de Sancho Sánchez de Muñón véase GONZÁlEz, “Un espía”, p. 105.

2 SANT'ANA, Elysio de Carvalho, um militante do anarquismo, pp. 22-23. 
criminalidad moderna, enfatizando el grado de sofisticación con que éstas proliferaban en las metrópolis del espacio atlántico a comienzos del siglo XX.

Anteriormente, el chico malo asaltó las carreteras, matando a la víctima y robándola. Ahora el malhechor se enriquece mediante transacciones astutas, realizadas en la bolsa de valores, fundando compañías financieras que ocultan en colosales estatutos scroqueries, firmando cheques falsos, falsificando dinero público lo cual modernamente se llama un delito financiero. Con una génesis más amplia que el Océano Atlántico y alimentada por la fiebre del oro tan típica de nuestro siglo, el crimen bancario es, por excelencia, el producto más perfecto de astucia y fraude. ${ }^{3}$

La fiebre especulativa que marcó la capital federal a finales del siglo xix e inicios del xx no solamente trajo consigo nuevos impulsos económicos, sino también ingeniosas prácticas delictivas de estafa y falsificación. Con el fin del régimen de esclavitud y el ingreso en masa de migrantes en territorio brasileño, la política de emisión de dinero alentó una mayor producción de papel moneda por medio de bancos privados y una expansión de la concesión de crédito para incentivar las transacciones económicas en Brasil. ${ }^{4}$ Los intensos movimientos financieros y la ambición conocida como febre do ouro - una búsqueda desenfrenada de enriquecimiento- representaban un nuevo escenario urbano en la capital federal, que entonces se constituía como un espacio por excelencia de renovadas interacciones monetarias y posibilidades de lucro. ${ }^{5}$ En este contexto, las bandas de falsificación de dinero, así como los golpes que defraudaban distintos papeles fiduciarios (cédulas, cheques, pólizas) se tornaban

3 Carvalho, A luta técnica contra o crime, pp. 24-25.

${ }^{4}$ Fausto, História do Brasil, p. 252.

${ }^{5}$ Sobre la fiebre del oro y el desarrollo de intrincados golpes criminales en Brasil y Argentina, véase Galeano, Criminosos. 
objeto de preocupación de las distintas autoridades policiales brasileñas, como el director del Gabinete de Identificación, Elysio de Carvalho.

$\mathrm{Al}$ afirmar que las falsificaciones tenían una "génesis más amplia que la del Océano Atlántico", Carvalho sugería que tales prácticas delictivas emergían en distintos países de Europa y América del Sur, atravesando las fronteras y permitiendo la circulación de innumerables estafadores entre las naciones de estos continentes. No fue casualidad que las fuerzas policiales de los países del espacio atlántico se dedicaran a estudiar las formas de criminalidad moderna y buscaran establecer formas de cooperación entre sí, con el objeto de localizar y castigar a quienes violaban las leyes. Según Elysio de Carvalho, "todos esos scrocs y maîtres-chanteurs, caballeros de la industria, eméritos profesionales, ostentando nombres ilustres yrespetables escudos de armas, tan falsos como sus personas, todos vienen del extranjero [...] pour faire l'Amérique". ${ }^{6} \mathrm{El}$ uso de la expresión "fazer a América" daba un sentido al carácter atlántico de las formas de criminalidad que pasaban a ser objeto de atención en el esfuerzo de Elysio de Carvalho: era una referencia directa al Atlántico de las migraciones masivas de europeos hacia las Américas, que llegaban a estas costas con la esperanza de mejorar sus condiciones de vida. ${ }^{7}$

La asociación entre el fenómeno de la inmigración y la emergencia de nuevas formas de delincuencia era un tema de la bibliografía criminológica que nutría los escritos de los policías a principios del siglo xx. El carácter transnacional que ganaba el fenómeno de la criminalidad moderna resultó en esfuerzos para construir espacios de intercambio de saberes ligados al campo de la policía científica que pretendían controlar tales prácticas ilícitas. La traducción de textos, la visita de criminales extranjeros

6 Carvalho, "Delinquência dos estrangeiros", p. 221.

7 Fausto, Fazer a América. 
y la participación en congresos internacionales daban cuenta de cómo el fenómeno de la criminalidad moderna se tornaba un problema de escala global, perteneciente a una agenda política que pensaba el internacionalismo como una respuesta posible para el control de las practicas criminales. ${ }^{8}$

De esta forma, a partir de un juego de escalas sobre problemas que atravesó la figura del funcionario de policía Elysio de Carvalho, este artículo tiene como objetivo analizar la emergencia de saberes policiales que colocaban bajo escrutinio los llamados delitos económicos, así como los sofisticados falsificadores que actuaban en la capital federal brasileña. Asimismo, mediante el análisis de las publicaciones dirigidas a los funcionarios policiales, los intercambios de correspondencia entre criminalistas y las participaciones en congresos internacionales, pretendo investigar el intercambio de una gama de saberes entre las policías sudamericanas y europeas, acerca de los delitos que colocaban en riesgo el patrimonio de las instituciones centrales del capitalismo financiero: las compañías de seguros y las instituciones bancarias.

\section{LAS FALSIFICACIONES Y LAS PRÁCTICAS}

DE ESCRITURA CRIMINAL

Cheques, pólizas, billetes y los más diversos tipos de documentos impresos con valor monetario se tornaron factibles de falsificar en Río de Janeiro durante los primeros años del siglo xx. No por casualidad, este asunto fue relevante para publicar la revista policial oficial del Gabinete de Identificación de Río de Janeiro, bajo el título de Boletim Policial, demostrando una clara preocupación en lidiar con las nuevas técnicas de robo utilizadas por los delincuentes cariocas. Casos como el del conocido falsificador de dinero Albino Mendes se dieron a conocer en el

${ }^{8}$ KNEPPER, The Invention of International Crime, p. 5. 
periódico del Gabinete como ejemplo de prácticas criminales modernas que envolvían vastas redes criminales de complicidad interestatal y transnacional. ${ }^{9}$ Equipados con gafas, ácidos, piedras para litografiar y máquinas fotográficas, estos bandidos, que muchas veces ostentaban vestimentas refinadas, se tornaban objetos de estudio de experticia policial, justamente por manipular códigos sociales que a primera vista los colocaban como ciudadanos que estarían "por encima de cualquier sospecha". ${ }^{10}$

Durante el primer año en que Elysio de Carvalho se tornó editor de esta revista fueron identificados cerca de 15 casos publicados en los informes policiales, donde se abordaban episodios de estafa ligados a la práctica de falsificación de diversos géneros. Tales informes eran seleccionados por el editor del periódico, creando un mosaico de episodios criminales registrados por los diferentes distritos policiales de la ciudad. De esta forma, la recurrencia de casos relacionados con falsificación, en detrimento de la incidencia de homicidio, violación o crímenes pasionales funcionaba como punto de apoyo para las publicaciones teóricas de la revista, justificando la necesidad de implementar los saberes de la policía científica para castigar a los falsificadores que circulaban por la ciudad.

De esta manera, Elysio de Carvalho publicó un primer artículo intitulado "La falsificación de nuestros valores circulantes" en la revista Boletim Policial. Al ocuparse del problema de la circulación de billetes falsos, con incidencia en tiendas, tranvías y estaciones ferroviarias de Río de Janeiro, el director del Gabinete de Identificación apuntaba cómo el crimen de falsificación

\footnotetext{
9 Sobre el falsificador Albino Mendes, véase Galeano, "Historia da moeda falsa”, pp.67-99.

10 El discípulo de Alphonse Bertillon, Rodolph Archibald Reiss (1875-1929), fue director del Laboratorio de Policía Técnica y titular de la Cátedra de Policía Científica en la Universidad de Lausana, Suiza, y se destacó como uno de los grandes exponentes para la consolidación del campo policial científico internacional a principios del siglo xx. QuINche, Sur les traces $d u$ crime.
} 
de dinero constituía una "industria inteligentemente organizada, muy rentable y practicada a gran escala". ${ }^{11}$ Surgiría así un tipo de criminalidad que no sería ocasional, sino más bien profesional, en la cual los falsificadores conformaron una "aristocracia de malhechores" dotada de "ciertas nociones científicas especiales, tales como químicos, electricistas, grabadores y litógrafos". ${ }^{12}$ Según el director del Gabinete de Identificación, lejos de actuar aisladamente, los falsificadores actuaban de forma asociativa, creando una red de colaboración en la cual cada uno desempeñaba su especialidad: unos fabricaban los billetes, mientras que otros trabajaban como intermediarios vendiéndolos a terceros y, por último, había aquellos que se encargaban de circularlos en las más diversas situaciones cotidianas de la capital federal.

La idea de clasificar a los delincuentes construyendo un mapa de sus hábitos y formas de actuar hundía sus raíces en el campo de la policía científica, específicamente en el manual de robos y homicidios escrito por el criminalista suizo Rudolph A. Reiss. ${ }^{13}$ De menores delincuentes a prostitutas, scrocs y falsificadores, el estudio de Reiss construía una división de oficios del crimen, en los cuales los malhechores presentaban no solamente diferentes habilidades, sino también jerarquías internas entre sí. Fue bajo la forma de "listas" que, en el siglo xix, las policías inscribieron diversos actores sociales marginalizados -como prostitutas, ladrones e indigentes- en una realidad específica, dando cierta coherencia al caos de la criminalidad. ${ }^{14}$ No era fortuito que el crimen, para Elysio de Carvalho, poseyera una

11 Carvalho, “A falsificação”, p. 591.

12 Carvalho, "A falsificação", pp. 591-592.

13 El discípulo de Alphonse Bertillon, Rodolphe Archibald Reiss (1875-1929), fue director del Laboratorio de Policía Técnica y titular de la Cátedra de Policía Científica en la Universidad de Lausana, Suiza, y se destacó como uno de los grandes exponentes para consolidar el campo policial científico internacional a principios del siglo xx. Quinche, Sur les traces $d u$ crime.

${ }_{14}$ Kalifa, Os bas-fonds, p. 128. 
"flora extraña y curiosa” y reclamara para sí una "historia natural" escrita, clasificando a sus protagonistas -esto es, los malhechores- con base en sus hábitos, fisionomías y modos de actuación criminal. ${ }^{15}$

El estudio de Dominique Kalifa muestra que las taxonomías de la criminalidad también poseían raíces en obras literarias policiales, como las Memorias de Vidocq. Publicada en 1828 por Eugène François Vidocq -director de la Sûreté Nationale-, la obra autobiográfica se basa en el pasado criminal del policía, bagaje que constituyó la materia prima de sus propias memorias. El libro fue considerado el texto "fundador de la modernidad policial" 16 y presentaba a Vidocq como un agente capaz de transitar entre el mundo del crimen y el de la ley. Los conocimientos adquiridos por su experiencia como delincuente no solamente le permitían entender el crimen, sino que lo capacitaban para combatirlo. En sus memorias, Vidocq se propuso clasificar las diferentes especies de malhechores, desde asesinos hasta estafadores, construyendo a partir del "método Lineu [...] una historia natural" 17 de los ladrones de París. En este sentido, Elysio de Carvalho construyó una taxonomía de los falsificadores de dinero en la convergencia entre los campos de saberes de la policía científica y la literatura del crimen que también circulaban a través del espacio atlántico.

Junto con los artículos teóricos de Elysio de Carvalho, el Boletim Policial publicó un estudio traducido del criminalista francés Edmond Locard, quien se dedicó a pensar las prácticas escritas delictuosas de los criminales. Director del Laboratorio de Policía Técnica en Lyon, Locard fue un gran interlocutor de Elysio de Carvalho durante el periodo en que ocupó el cargo de director del Gabinete de identificación. En este momento, su

15 Carvalho, “O mundo dos criminosos", p. 202.

16 Kalifa, Os bas-fonds, p. 130.

17 Kalifa, Os bas-fonds, p. 130. 
aparición en el Boletim Policial se restringió a arrojar luz sobre técnicas para detectar las prácticas de falsificación de monedas acuñadas en metálico o impresas sobre papel, entre otros documentos escritos. Para Locard, era responsabilidad del investigador comparar la composición de las monedas y los billetes incautados con el polvo y el barro encontrados en la casa y en las vestimentas de los acusados, procediendo así a un análisis químico y cualitativo. ${ }^{18}$ La fotografía y las microfotografías de los billetes falsificados también fueron colocados como recursos fundamentales, capaces de detectar los matices y las menores imperfecciones en el papel moneda. El impacto de estas teorías en los procedimientos del Gabinete de Identificación de Río de Janeiro ya se podía sentir en los escritos de Elysio de Carvalho que exhibían fotografías de billetes falsificados retirados para su repatriación.

Con la intención de colocar a los policías lectores al tanto de las posibilidades de detección de estos objetos, tales imágenes venían a demostrar los pequeños indicios y fallas que indicaban la falsedad de estos objetos monetarios. En este momento, resurgía en el Boletim Policial un paradigma indiciario que reivindicaba para sí las formas de distinguir el conocimiento verdadero de aquel que era falso. ${ }^{19}$ Así, la fotografía no sólo fue utilizada como una herramienta capaz de reproducir para los lectores las imágenes de los billetes falsificados, sino también como un instrumento de trabajo que permitía verificar la autenticidad del dinero y, por ende, comprobar su valor monetario.

La relación entre el progreso tecnológico y las nuevas formas en que se cometían los delitos financieros era uno de los puntos centrales en la bibliografía producida por la policía científica. Dichos libros daban a conocer los escritos de los policías en el inicio del siglo xx. Para Elysio de Carvalho, si la modernidad

18 LocARD, “Laboratórios de polícia e instrução criminal”, pp. 89-105.

19 Ginzburg, Mitos, pp. 169-180. 


\section{Imagen 1}

Fotografía DE BILLETES FALSIFICADOS

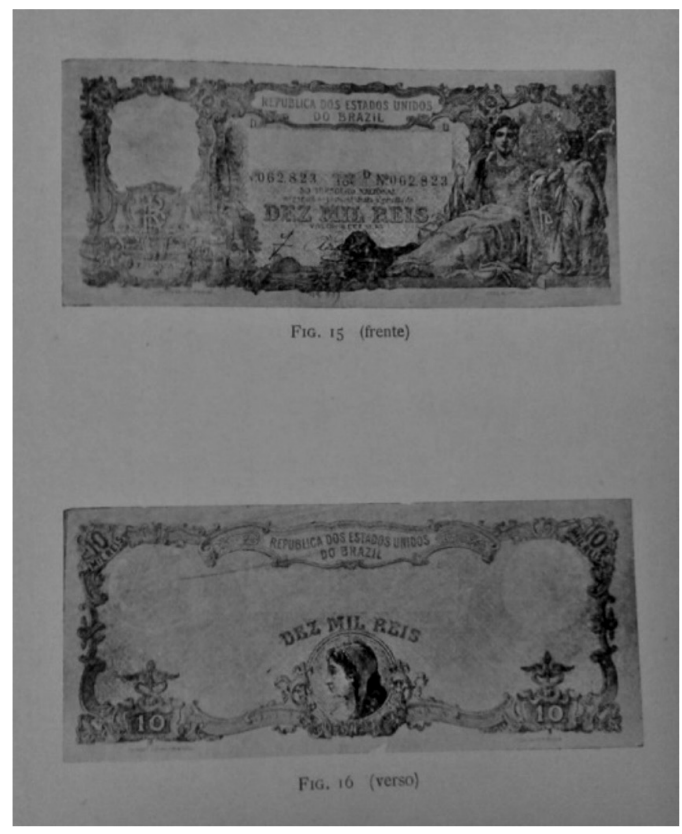

Fuente: Boletim Policial, v: 18-20 (oct.-dic. 1911).

traía una serie de avances para la humanidad, también contribuía a perfeccionar las técnicas de los delitos empleados por los criminales. Con esto se refería esencialmente a los medios de comunicación, los vehículos y transportes, así como a nuevos saberes e invenciones que se produjeron a principios del siglo xx. Los criminales conseguían manipular las técnicas modernas que les permitían realizar ingeniosos golpes. Para tal fin, la policía se debía medir con los criminales, profesionalizarse y volverse científica. Sólo de esa forma conseguiría combatir las formas modernas de criminalidad. Frente a eso, el director del Gabinete de Identificación de Río de Janeiro señalaba la necesidad 
de consolidar una policía igualmente moderna, capaz de aplicar "nociones, conocimientos, reglas, procesos y métodos científicos a la investigación criminal, desde el lugar del crimen hasta la determinación de la identidad del criminal". Los avances de los saberes científicos eran aquí defendidos como expertise policial necesario para combatir la criminalidad.

Tal ambigüedad frente a la modernidad surgió en los escritos de Elysio de Carvalho como fruto de un mosaico de lecturas. Acaso su principal referencia permite señalar el estudio desarrollado por el criminalista suizo Rudolph Archibald Reiss -principalmente, su lección de apertura en la cátedra de fotografía científica de la Universidad de Lausana-. Tal texto fue traducido y comentado por Elysio de Carvalho en el primer número de la revista Boletim Policial, demostrando no solamente una semejanza de ideas, sino también una similitud entre las estructuras textuales de las obras de Elysio de Carvalho y las del criminalista suizo. Si para Reiss "la humanidad progresa. Pero progresa tanto del lado del bien, como del lado del mal", ${ }^{20}$ para Elysio de Carvalho "el mundo pasó en estos últimos tiempos por transformaciones espantosas [...]. La obra del progreso, sin embargo, es indiferente: tanto favorece el bien como el mal". ${ }^{21}$ Si tal aproximación nos indica los procesos de difusión de los estudios de Reiss entre los criminalistas sudamericanos, Bunker nos señala cómo la teoría que asociaba a la modernidad con el avance de las técnicas de los criminales -denominada violence à vol- tenía amplia circulación al final del siglo xix, llegando a incluir textos de carácter más sociológico, como los "Discursos en Elberfeld" de Frederich Engels. ${ }^{22}$ De esta forma, se tornaba evidente la generalización de un cierto desencanto con la

20 ReIss, “Os métodos científicos”, p. 16.

21 Carvalho, “A Polícia Moderna”, Ilustração Brasileira (1o jul. 1910).

22 Sobre la teoría de la violencia, véase Bunker, "El robo-homicidio”, pp. 405-425. 
modernidad en relación con el fenómeno de la criminalidad que trascendía las fronteras del estado-nación brasileño.

Durante las dos primeras décadas del siglo xx, Reiss ya era conocido por sus exitosos trabajos sobre la falsificación de moneda. ${ }^{23}$ En sus estudios teóricos traducidos y publicados por la revista Boletim Policial, el criminalista suizo resaltaba la importancia de los procesos gráficos en la impresión del papel moneda como forma de evitar su falsificación. Por más que ningún material fuese imposible de falsificar, sería necesario "acumular dificultades, protegiendo así al público” de los falsificadores. ${ }^{24}$ La necesidad de elaborar un papel moneda "fuerte" 25 fue una idea resaltada en los escritos policiales de Elysio de Carvalho ${ }^{26}$ y del primer delegado auxiliar, Leon Roussoulieres. ${ }^{27}$ Frente a la fragilidad del papel moneda brasileño y las complejas redes de falsificación de los criminales, el director del Gabinete de Identificación indicaba cómo la falta de materiales y elementos técnicos de la policía de Río de Janeiro era un obstáculo para la erradicación de esta práctica delictiva en la ciudad.

Sin embargo, el acercamiento entre las secciones especializadas de la policía de Río de Janeiro y Lausana no se restringía a una sola dirección. Es decir, no puede interpretarse como mero proceso de difusión de saberes europeos hacia una periferia latinoamericana. Según el director del Gabinete de Identificación, la producción de dinero falso ocurría en una ruta que transitaba

${ }^{23}$ Nicolas Quinche narra en su trabajo el episodio en el que Reiss pudo mapear la procedencia de billetes falsos ubicados en el Banco de Francia, cuyo responsable era el propietario de una fábrica de billetes falsos en Lausana. Este caso ganó notoriedad en países como Francia, Italia y Suiza, y lo consagró como el principal experto en la investigación de dinero falsificado. Véase Quinche, Sur les traces du crime, pp. 288-292.

${ }^{24}$ Reiss, Polícia Técnica, p. 24.

25 Reiss, Polícia Técnica, p. 24.

${ }^{26}$ Este argumento fue identificado en el segundo texto de Elysio de Carvalho sobre falsificación de dinero. CarvalHo, "A nossa moeda papel”, pp. 107-109. 27 Roussoulı̀̀res, “A falsificação”, pp. 348-350. 
por el Río de la Plata, abarcando territorios de las naciones brasileña, argentina y uruguaya. ${ }^{28} \mathrm{La}$ amplitud de la red de actuación de falsificadores sudamericanos llamaba la atención de criminalistas extranjeros, como el propio R. A. Reiss. No por casualidad, el criminalista suizo realizó una serie de conferencias en São Paulo y Río de Janeiro, abordando precisamente la temática de la falsificación monetaria. Discípulo de Alphonse Bertillon y director del Instituto de Policía Científica de la Universidad de Lausanne, su estancia en Brasil fue organizada, primeramente, por la policía del estado de Sao Paulo, llegando a Río de Janeiro por la mediación de Elysio de Carvalho con el jefe de la policía Edwiges Queiroz..$^{29}$ Según Reiss, las conferencias impartidas en otros países eran fundamentales para consolidar a la policía como una institución moderna, teniendo en cuenta que el crimen se había tornado un fenómeno transnacional. ${ }^{30}$

Durante sus clases, Reiss apuntó la fragilidad de los billetes brasileños, toda vez que sus características y procesos gráficos los volvían susceptibles de ser falsificados. La impresión de grabados gruesos y el uso de papeles que no estaban afiligranados eran citados por el criminalista como elementos que permitían a los falsificadores forjar billetes sin dificultad. Al final de su conferencia, Reiss describió que, en una época de grandes conflictos bélicos en el mundo occidental, el espacio atlántico sudamericano sería un terreno propicio para el crecimiento y el liderazgo de las formas de cooperación entre las policías científicas del mundo.

Por lo tanto, la unión policial internacional debe ser tratada seriamente. Tal vez no sea posible para las naciones europeas, debido a las delicadezas de su vida política internacional, llamar a esta

28 Galeano, “Un artista del delito”, pp. 195-233.

29 Boletim Policial (jul. 1913).

30 Reiss, Polícia Técnica, p. 24. Sobre la experiencia de Reiss en São Paulo, véase MARTins, “A civilizaçao”, pp. 224-236. 
iniciativa por sí mismas. Está naturalmente indicado para un país neutral, ignorante de estas luchas de cancillería; y tal vez Brasil sería bienvenido para tal propuesta. ${ }^{31}$

La idea de que un país latinoamericano pudiese liderar las policías científicas demostraba que se trataba de un campo compuesto por diversos polos de producción de saberes, y que dichos polos no se relacionaban de forma pasiva entre sí. Sin embargo, por más que los discursos oficiales buscaron enaltecer las fuerzas policiales que fraguaban tales alianzas, éstas ocurrían en desigualdades de poder, teniendo en cuenta no sólo lo incipiente del campo, sino también las asimetrías del incentivo presupuestario otorgado por los estados europeos para construir sus instituciones policiales.

La invitación al criminalista para la realización de un curso de formación de los agentes de Río de Janeiro convergía con la propia fundación de la Escuela de Policía de "preservación de la propiedad particular” en Brasil. ${ }^{32}$ En un artículo publicado en el Boletim Policial, Elysio de Carvalho indicó cómo las prácticas de falsificación movilizaban instituciones financieras internacionales que buscaban controlar la emisión de papel moneda falsificado. Fue el caso de la American Bank Note, un "establecimiento que garantizó que los billetes salidos de sus ateliers vencerían la astucia de los más hábiles falsificadores". ${ }^{33}$ Según Mihm, desde el inicio del siglo xIx, la producción oficial de los billetes todavía no estaba centralizada, puesto que también ocurría la emisión de monedas por bancos privados, lo que facilitaba la acción de los falsificadores de dinero. ${ }^{34} \mathrm{El}$ fracaso de la American Bank en la emisión que le era encomendada exhibió, por un lado, la magnitud de la fuerza que movilizaba a

\footnotetext{
31 Reiss, Polícia Técnica, pp. 39-42.

32 Carvalho, "História Natural dos Malfeitores”, p. 61.

33 Carvalho, “A nossa moeda”, p. 107.

${ }^{34}$ Minm, A Nation of Counterfeiters.
} 
los falsificadores en diferentes espacios geográficos. Por el otro, mostró los percances de las instituciones financieras en el proceso para consolidar un orden cambiario de corte capitalista en Brasil. Lejos de ser lineal, la inserción de Brasil en el capitalismo financiero internacional enfrentó -más allá del desafío de una transición del sistema de mano de obra esclava al trabajo asalariado- las dificultades de preservar el patrimonio y consolidar sus instituciones bancarias. ${ }^{35}$ No fue obra de la casualidad que en las conferencias realizadas en São Paulo Reiss apuntó que los estudios de policía científica sobre la falsificación monetaria eran de interés "de los banqueros y de los grandes comerciantes". ${ }^{36}$ Frente al fenómeno de la falsificación monetaria, que alcanzaba una escala internacional, los criminales ligados al campo de la policía científica reivindicaban para sí la capacidad de proteger los capitales de los grandes negociantes y de las instituciones bancarias internacionales que actuaban en el Brasil de principios del siglo xx.

De esta manera, el análisis clásico de Caio Prado Júnior presenta una imprecisión al señalar a Brasil como un lugar "seguro para la inversión de capitales" extranjeros durante este periodo. ${ }^{37}$ Los intensos movimientos económicos marcados por las actividades especulativas generaban lucro y crisis financiera, además de la formación de redes de estafadores que buscaban enriquecerse en detrimento del patrimonio de los banqueros y de los grandes comerciantes capitalistas. En este sentido, cabe reconocer que el proceso de inserción de Brasil en el sistema capitalista financiero internacional se constituyó como un fenómeno complejo, atravesado por fisuras e inestabilidades que afectaban la actuación y el proceso de consolidación de las instituciones bancarias en el país.

35 JúNIOR, História econômica, p. 170.

36 Reiss, Polícia Técnica, p. 22.

37 JúnIOR, História econômica, p. 218. 
Fue dentro de este contexto que la obra de Edmond Locard ganó espacio en las páginas del Boletim Policial, abriendo una nueva dimensión analítica para una experticia policial: los estudios sobre la escritura criminal. Se buscaba estudiar desde la falsificación de títulos, pólizas, cheques o papeles fiduciarios de todo tipo cuya firma o incluso el mismo documento podían ser objeto de falsificación. La figura del policía que escribía traía consigo un segundo personaje que sería al mismo tiempo su objeto y su antagonista -el criminal letrado- que justamente por medio de la escritura forjaba formas de burlar las leyes. ${ }^{38}$ Artículos como "Pericia Gráfica" y "Laboratorios de Policía y la Instrucción Criminal" 39 fueron traducidos para el periódico policial brasileño, trayendo como tema la falsificación de escritos por parte de criminales. Surgían así saberes cada vez más técnicos -utilizando reactivos, iluminaciones en transparencia, exámenes microscópicos-capaces de detectar falsificaciones escritas hechas por raspado, sobrecarga o por imitación grafológica. En estos textos, se impulsaba una conexión entre el agente policial que estaría en las calles, los delegados que actuaban en la burocracia policial y el encargado de las tareas periciales. Tal colaboración y jerarquía, que conectaba el espacio de la calle con el laboratorio policial, era defendida como un proyecto capaz de controlar las prácticas criminales que tenían la escritura como su modus operandi.

En tanto, el diálogo de Elysio de Carvalho con los escritos de Locard estuvo lejos de resultar en una importación de saberes franceses a la policía brasileña. Al contrario, la relación entre los intelectuales se mantenía por medio de intercambios concretos y formaban puentes que conectaban las policías de Lyon y de Río de Janeiro. En una de las cartas dirigida a Elysio de Carvalho por Edmond Locard, invitó al director del Gabinete

38 ARtières, La police de l'écriture, p. 18.

39 Locard, "Perícia Gráfica”, pp. 304-311 y “Laboratórios”, p. 89. 
de Identificación de Río de Janeiro a presentar los principales trabajos desarrollados por esta división de policía en la sección de "Policía de las Ciudades y Laboratorios de Policía", que se llevaría a cabo en la Exposición Internacional y Urbana de Lyon. En este evento fue reservada una sección especial para los trabajos de policía científica, incluyendo los estudios sobre falsificación de dinero. El Boletim Policial fue citado por Locard como un material destacado producido por la sección policial carioca que sería de gran interés para la composición de esta exposición. ${ }^{40}$ Así, el Boletim Policial se convirtió en un instrumento de cooperación capaz de consolidar la inserción de la institución carioca en una red internacional.

En este sentido, con el propósito de divulgar y consolidar estos intercambios entre el Laboratorio Policial de Lyon y el Gabinete de Identificación de Río de Janeiro, Elysio de Carvalho publicó la comunicación que envió a la Exposición Internacional Urbana como uno de los folletos de la Biblioteca do Boletim Policial. El esfuerzo de profundizar las relaciones "con eminentes profesionales extranjeros" fue registrado en el informe escrito por el director del Gabinete de Identificación. ${ }^{41}$ En su comunicación, Elysio de Carvalho enumeró los diferentes conocimientos y campos de actividad de esta división: desde las inspecciones fotográficas en las escenas del crimen, la identificación de criminales y cadáveres, junto con la organización de estadísticas criminales y la elaboración del Boletim Policial. Se enviaron a la Exposición muestras de cheques falsos y papel moneda brasileños, así como de escrituras falsificadas confiscadas por la policía de Río de Janeiro. ${ }^{42}$ Estos intercambios concretos entre la Oficina de Identificación y el Laboratorio de Policía Científica de Lyon mostraron cómo se estaba forjando un mapa

\footnotetext{
40 "Exposição", pp. 258-259.

41 Carvalho, "Relatório", p. 21.

42 Carvalho, L'organisation, p. 21.
} 
internacional de la policía científica que buscaba reflexionar sobre el fenómeno de la delincuencia moderna, en el que los países latinoamericanos obtuvieron mayor visibilidad. Como era de esperar, en una cita a Locard, Elysio de Carvalho registró cómo el experto de Lyon percibió el avance de los países latinoamericanos en el campo de la policía científica.

Una vez más, el buen ejemplo nos llega a través de los países de América Latina. Estos países jóvenes tienen la energía para cambiar radicalmente su funcionamiento administrativo cuando sea necesario [...] Contentémonos con admirar el espíritu de iniciativa de estos latinos renovados al otro lado del Atlántico y aplaudir la sabiduría de sus instituciones..$^{43}$

Tales discursos, que a menudo obedecían a una serie de procedimientos discursivos laudatorios, por tratarse precisamente de construir formas de cooperación policial, podrían enmascarar las jerarquías existentes entre la policía europea y la latinoamericana. Sin embargo, el discurso de Locard reveló dinámicas transatlánticas intensas que afectaron, desde fines del siglo XIX, la construcción de la policía sudamericana. Tales artefactos que circulan en exhibiciones internacionales de policía científica, tanto proyectaron a la policía de Río en el campo criminalístico internacional, como contribuyeron a la composición de materiales policiales de estos países. En este contexto, el estudio publicado en el Boletim Policial y enviado a la Exposición de Lyon se publicó en los Archives d'Antropologie Criminelle, indicando un momento de consagración de la figura de Elysio de Carvalho en el campo criminalístico francófono de la policía científica. Fundado en 1886 por el criminalista francés Alexandre Lacassagne, los Archives d'Antropologie Criminelle fueron una de las

${ }^{43}$ Edmond Locard citado en Carvalho, L'organisation, p. 28 [traducción de la autora]. 
primeras revistas académicas en francés dedicadas al estudio de la criminalística, convirtiéndose en una de las principales publicaciones científicas de principios del siglo xx. La aparición de un artículo en esta revista académica significó la consagración de la figura de Elysio de Carvalho en el campo francófono de la policía científica y, sobre todo, la inserción de polos de policía sudamericanos más allá de la posición de receptores de conocimiento. En este sentido, sería a través de las fisuras que impregnaban la consolidación del sistema capitalista financiero internacional, en medio de la articulación de redes de falsificadores que operaron allende las fronteras de los países, que se forjaron los lazos de cooperación entre la policía sudamericana y la europea.

\section{“LA INDUSTRIA DEL FUEGO”}

Los análisis en el campo de la policía científica también se dedicaron a un segundo espectro de estudio: las escenas del crimen. Casas robadas, lugares donde se cometieron asesinatos y establecimientos incendiados estaban sujetos a escrutinio por parte de expertos policiales que buscaban dilucidar crímenes complejos cuya autoría no podía identificarse al principio. En medio de la necesidad de hacer del Gabinete de Identificación de Río de Janeiro apto para realizar el análisis de la escena del crimen, Elysio de Carvalho escribió el estudio "Los métodos de la policía científica: el papel de la fotografía en las investigaciones judiciales". Primero impreso como un artículo y luego como un libro en la colección de la Biblioteca del Boletim Policial, la intención de esta publicación era demostrar la relevancia del uso de instrumentos fotográficos para analizar los vestigios encontrados en las escenas del crimen: desde registrar la posición exacta del cadáver, la apariencia de la ropa del muerto, etc. hasta descubrir rastros de soluciones inflamables, lo cual fue posible gracias a nuevos inventos y reactivos. 
El gabinete de identificación realizó investigaciones sobre la escena del crimen en los casos donde se produjeron incendios en Río de Janeiro. Para Elysio de Carvalho, habría una verdadera "industria de incendios", conformada por "comerciantes en bancarrota o propietarios codiciosos" que buscaban salir de la "vergüenza material" por medio de la compensación que otorgaban las compañías de seguros. Con el uso de materiales inflamables, como soluciones de fósforo y sulfuro de carbono, provocaron incendios con el propósito de adquirir el valor de las pólizas. ${ }^{44}$ Desde finales del siglo XIx, la figura del capitalista era conocida como una fuerza impulsora del desarrollo económico mediante iniciativas relacionadas con la industria o incluso inversiones en los sectores de servicios públicos. Sin embargo, tales actividades, a menudo marcadas por prácticas especulativas, dieron como resultado la creación de compañías económicamente inviables que lanzaron títulos de deuda en la bolsa, causando pérdidas a cientos de inversores. ${ }^{45}$ De esta manera, el incendio de establecimientos comerciales se convirtió en una solución a las iniciativas económicas fallidas, permitiendo la liquidación de deudas mediante la compensación recibida por las compañías de seguros. Dependía de la policía distinguir los incendios accidentales de los destinados al autoenriquecimiento a expensas de la fortaleza económica de las aseguradoras.

Con este fin, el uso de tecnologías fotográficas en el análisis pericial demostró ser una posibilidad para detectar las estafas que afectaron a estas instituciones. Defendido como el "dispositivo registrado que todo lo ve y todo fija, con fidelidad y claridad", para Elysio de Carvalho, la fotografía sería "la retina del hombre de ciencia" y, parafraseando al criminalista suizo Rudolph Archibald Reiss, "la memoria artificial del juez". ${ }^{46}$

\footnotetext{
${ }^{44}$ Silva, "Nos trilhos do capital", p. 551.

${ }^{45}$ Silva, "Nos trilhos do capital", p. 551.

46 Carvalho, "Os métodos da polícia", p. 308.
} 
Frente a los detalles que podrían escapar al análisis policial y al alto riesgo de contaminación de la escena del crimen, la fotografía funcionaría como una tecnología capaz de reproducir diferentes perspectivas de las escenas del crimen que ni siquiera el ojo humano vigilante podría captar.

Desarrollada en el siglo xIx, la cámara funcionaba como un dispositivo tecnológico capaz de mediar la figura del operador y el modelo, produciendo una imagen cuyo significado estaba cargado de objetividad en relación con el objeto o la persona que fue fotografiada. ${ }^{47} \mathrm{La}$ inclusión de fotografías en el campo científico inauguró una serie de estudios sobre los más variados temas: desde paisajes hasta animales, desde monumentos hasta obras de arte, y, por supuesto, hasta delincuentes y escenas del crimen. La nueva tecnología no sólo permitió la grabación, sino también la reproducción en serie de imágenes a través de las cuales fue posible construir narrativas mediante su visualización secuencial. ${ }^{48}$ No es sorprendente que Elysio de Carvalho enfatizara cómo el uso de fotografías en audiencias o juicios permitió que el aspecto de la escena del crimen "casi siempre completamente desconocido para la mayoría de los llamados a servir en el proceso" se presentara objetivamente. ${ }^{49}$ Dicha tecnología también permitió el registro de pequeños detalles como huellas, impresiones papilares y registros de pólvora que podrían servir para identificar tanto la naturaleza del delito como a quienes lo cometieron. Ante esto, en un artículo publicado en el Boletim Policial, Elysio de Carvalho reafirmó la necesidad de "conocimiento técnico" y "educación profesional previa" 50 para los expertos asignados al análisis pericial de incendios.

Entre estos conocimientos criminalísticos, los estudios producidos por Elysio de Carvalho sobre las escenas del crimen

\footnotetext{
47 Rouillé, A fotografia, p. 36.

48 Rouillé, A fotografia, p. 38.

49 Carvalho, "Os métodos da polícia”, p. 309.

50 Carvalho, "A indústria dos incêndios", p. 471.
} 
tomaron como referencias principales los trabajos de Alphonse Bertillon, creador del Servicio de Identificación Judicial de París, y Rudolphe Archibald Reiss, director del Laboratorio de Policía Científica de Lausana. Tales elecciones teóricas no fueron meras coincidencias, sino que evidenciaron intercambios concretos entre la policía sudamericana y la europea, especialmente frente a problemas comunes. En consecuencia, la invención de la fotografía judicial métrica, creada por Alphonse Bertillon, ganó un espacio especial en el estudio de Elysio de Carvalho. Según el director del Gabinete de Identificación, dicho método, al aplicar "los principios fundamentales de la perspectiva" a la fotografía, “permitió la reconstrucción de las distancias y dimensiones reales de los objetos representados en la prueba". ${ }^{51} \mathrm{Al}$ analizar la documentación del Boletim Policial, fue posible detectar la presencia de una copia de la cámara métrica creada por Bertillon en la colección del Gabinete de Identificación y Estadísticas de Río de Janeiro. Fabricado por la casa Lacour-Berthiot, dicho dispositivo fue comprado en Europa y realizado a partir de otras tecnologías fotográficas también desarrolladas por el criminalista francés: una máquina de señalización, una máquina de ampliación, un reproductor de chips y una caja 'Bertillon' para el transporte de objetos que contienen huellas digitales. ${ }^{52}$

No por casualidad, el director del Gabinete de Identificación y Estadística envió su estudio sobre el papel de la fotografía en las investigaciones judiciales a Alphonse Bertillon. En respuesta, el criminalista francés envió una carta a Elysio de Carvalho no sólo agradeciéndole por enviar una copia de su trabajo, sino también elogiando sus esfuerzos por "organizar una tecnología policial” en Brasil. ${ }^{53}$ Junto con la correspondencia, el criminalista francés envió una pequeña colección de 39 tipos de

51 Carvalho, “Os métodos da polícia”, p. 310.

52 Carvalho, “Os métodos da polícia”, p. 317.

53 Alphonse Bertillon, "Relações com profissionais estrangeiros”, citado en Carvalho, "Relatório", p. 25. 
mechones de cabello de 10 gramos, cada uno de los cuales fue clasificado de acuerdo con criterios científicos. ${ }^{54}$ La publicación de la carta de Bertillon demostró los esfuerzos del gabinete para insertarse en un campo de conocimiento criminal internacional, así como para indicar rastros de intercambios concretos en prácticas de cooperación entre la policía europea y la sudamericana.

De acuerdo con las estadísticas presentadas por el director de este departamento policial, fueron registrados 1571 incendios entre los años de 1902 y 1913, habiendo un claro incremento de estos episodios con el paso de los años. Si en 1902 ocurrieron 82 episodios, en 1907 fueron identificados 139 y en el penúltimo año de la gestión de Elysio de Carvalho, 244. ${ }^{55}$ Estas estadísticas demuestran no solo un crecimiento de los episodios de incendio en la capital federal, sino también un mayor esfuerzo para registrar e investigar tales incidentes, especialmente durante el período en el que Elysio de Carvalho fue director de la Oficina de Identificación. En 1911, las estadísticas apuntaban 190 casos de incendio, mientras que en 1912 sumaron 186, y en 1913 ascendieron a 244. Según el escritor alagoano, en el año actual de publicación:

[...] todos estos incendios fueron en establecimientos comerciales o industriales; todos, mas todos estos negocios estaban asegurados, casi todos tuvieron lugar de noche; todos menos uno fue calificado por los expertos designados por la policía como casual, y en sólo dos casos los tribunales pudieron denunciar a los autores, y esto a través de la aplicación de métodos científicos de verificación. ${ }^{56}$

De esta forma, por medio de estudios sobre las investigaciones de escenas del crimen y su difusión en publicaciones, el

${ }^{54}$ Alphonse Bertillon, "Relações com profissionais estrangeiros", citado en Carvalho, "Relatório", p. 25.

55 Carvalho, "A indústria dos incêndios", p. 191.

56 Carvalho, "A indústria dos incêndios”, p. 191. 
director del Gabinete de Identificación demostraba la pertinencia de los avances de la policía científica para un nuevo agente social prominente en el sistema capitalista financiero internacional: las compañías de seguros. A partir de finales del siglo XIX, la dimensión global que alcanzó la dinámica económica del capitalismo financiero tuvo como uno de sus pilares los sistemas bancarios, los sistemas de crédito y las agencias de seguros. ${ }^{57}$ Las industrias de seguros tenían como actividad la objetivación racional de los riesgos, transformando bienes, servicios o ideas en productos a los que se atribuía un valor económico. ${ }^{58}$ Sólo en caso de accidentes, las aseguradoras como garantes del riesgo eran responsables del pago de indemnizaciones correspondientes al valor de la propiedad perdida. Estas empresas se consolidaron a través de una red de interdependencia transnacional y protegieron, sobre todo, el capital de los grandes centros económicos del orden internacional. ${ }^{59}$ Por tanto, al demostrar la pertinencia del conocimiento de la policía científica para los casos de incendios criminales, Elysio de Carvalho defendió que la sección del Gabinete de Identificación y Estadística no sólo podía garantizar la propiedad privada, sino también proteger una de las instituciones centrales del capitalismo financiero.

Los esfuerzos de aproximación con los criminalistas europeos también respondieron a las dinámicas y disputas internas presentes entre los departamentos de policía de Río de Janeiro. El sector de fotografía judicial de la Oficina de Identificación y Estadística se estableció con la reforma de 1907, teniendo entre sus funciones "ayudar al Servicio Médico Legal a identificar cadáveres desconocidos, confrontar y examinar manchas, impresiones invisibles reveladas y fotografías de la escena del

57 Gonçalves, “A 'foice de dez reis'”, p. 3.

58 Gonçalves, “A 'foice de dez reis'”, p. 3.

59 Gonçalves, “A 'foice de dez reis"”, p. 28. 
crimen" ${ }^{60}$ Así, el conocimiento de la fotografía permitió que el Gabinete de Identificación ganara atribuciones que fueron más allá de su división y avanzó frente a otra sección policial especializada, también basada en el conocimiento científico: el Servicio Médico Legal. Ante estas disputas por el espacio, la mejora de las tecnologías de la fotografía judicial, así como la articulación con importantes criminalistas europeos, constituyeron estrategias llevadas a cabo para fortalecer el Gabinete de Identificación y Estadística entre las otras secciones especializadas de la policía de Río de Janeiro. No fue fortuito que en el periódico Gazeta de Noticias, la sección del Gabinete de Identificación fuera colocada como el Gabinete "de donde depende la organización moderna de toda policía bien organizada”, ${ }^{61}$ y fue considerada como el pivot da polícia. De esta forma, al ensayar un proyecto para el control y combate de incendios provocados, Elysio de Carvalho buscó proyectar al Gabinete de Identificación como un eje conductor de ese proceso de modernización de las fuerzas policiales que tuvo como punto de partida la reforma de 1907.

Sin embargo, los avances tecnológicos obtenidos por el Gabinete de Identificación no implicaron una aplicación diaria de este conocimiento en las prácticas de investigación criminal. Según los informes realizados por las comisarías de policía, eran recurrentes los problemas del Gabinete para realizar las investigaciones en los lugares donde ocurrieron crímenes. Al inspeccionar una escena del crimen, Elysio de Carvalho informó que era imposible extraer las huellas dactilares dejadas por un ladrón sobre la bandera de una de las puertas interiores de un edificio donde se había producido un robo. ${ }^{62}$ Además, eran frecuentes los episodios en que estas escenas estaban desprotegidas y

60 El artículo 122 del decreto $n^{\circ} 6440$ de Alfredo Pinto (30 de marzo de 1907) apareció reproducido en CARvalHo, “Os métodos da polícia”, p. 313.

61 “X. Gabinete de Identificação”, Gazeta de Notícias (10 nov. 1907).

62 "Notícias policiais", Boletim Policial (ago.-dic. 1911). 
eventualmente alteradas, o incluso situaciones en las que los empleados del Gabinete de Identificación ni siquiera eran llamados para investigar las escenas del crimen. ${ }^{63}$

Las estadísticas elaboradas por el Gabinete de Identificación y publicadas en el Boletim Policial indicaron cómo el Servicio de Fotografía realizó un volumen mucho mayor de registros criminales para los documentos de identificación que para las investigaciones de escenas del crimen. Entre los años 1908 y 1913, el departamento de policía de Río de Janeiro realizó 9344 registros fotográficos de delincuentes y 15784 registros para la producción de documentos de identificación. Durante este mismo periodo, el Gabinete reprodujo sólo 219 fotografías de escenas del crimen y un total de 15 sitios de incendios. De este modo, podemos notar cómo los esfuerzos de construcción de un laboratorio de policía científica tropezaron con la falta de aplicación de este conocimiento en la realización de investigaciones policiales respecto a casos de incendios. A partir de las cifras presentadas anteriormente, en lugar del registro de un gran número de incendios provocados, el director del Gabinete de Identificación trató de demostrar, a partir de una reducida muestra de casos, la importancia del conocimiento científico policial para preservar el patrimonio de las compañías de seguros. Por tanto, en lugar de responder a la demanda de estas instituciones, Elysio de Carvalho buscó obtener el apoyo de las aseguradoras para consolidar el campo de la policía científica dentro de la institución policial de Río de Janeiro.

Sin embargo, las bajas estadísticas de incendios criminales fueron justificadas por el autor como resultado de "velhas usanças e praxes empíricas" 64 utilizadas por los responsables de las investigaciones policiales. No es casualidad que, en medio de tales episodios, el Gabinete de Identificación emitiese circulares

63 Carvalho, “Os métodos da polícia”, p. 316.

64 Carvalho, “A indústria dos incêndios”, p. 471. 
explicando las precauciones necesarias para preservar y analizar las escenas del crimen. Para reemplazar el antiguo proceso descriptivo de los informes con el uso de la técnica fotográfica, este departamento de policía solicitó a sus agentes que cerraran la escena del crimen para evitar posibles modificaciones o, incluso, la desaparición de la evidencia criminal a causa de la entrada de extraños. $^{65}$

Como segunda estrategia, durante la estadía de Reiss en São Paulo, el criminalista suizo fue invitado a realizar la inspección pericial de un incendio ocurrido en una sastrería de la ciudad. La tragedia, que parecía ser accidental, fue desenmascarada por Reiss quien, al inspeccionar el sitio, encontró rastros de aceite en las telas de la tienda. Esta evidencia mostró que el sastre había incendiado su tienda para recibir una indemnización por el incendio. ${ }^{66}$ Reiss relató este caso en un periódico serbio de amplia difusión llamado Politka durante el periodo en que el criminalista había actuado en los campos de batalla de la primera guerra mundial. El gobierno serbio necesitaba el conocimiento fotográfico en el análisis de la escena del crimen como un medio de registro de los crímenes de guerra y las atrocidades cometidas por las tropas austrohúngaras. ${ }^{67}$ En 1922, Reiss publicó una serie de informes de la policía científica en la revista serbia Politka con el objetivo de "divulgar" ese conocimiento, demostrando la relevancia de este campo de conocimiento en un público más amplio ${ }^{68}$ Entre los artículos se abordó la experiencia de São Paulo, quedando en evidencia los múltiples circuitos que involucraron la circulación transnacional de conocimientos de la policía científica. De esta forma, la visita del criminalista suizo generó narrativas que superaron los límites geográficos locales, favoreciendo la circulación y difusión de experiencias y

${ }^{65}$ Carvalho, “Os métodos da polícia”, p. 316.

${ }^{66}$ Quinche, Crime, science et identité, p. 50 [traducción de la autora].

${ }_{67}$ Quinche, Crime, science et identité, p. 21.

${ }^{68}$ Quinche, Crime, science et identité, p. 21. 
formas de cooperación entre las policías brasileña y suiza para las naciones que desconocían el fenómeno de la criminalidad moderna brasileña.

Esa aproximación con la policía de Lausana indica cómo la construcción del campo de policía científica en Brasil y la inserción del Gabinete de Identificación de Río de Janeiro obedecieron a dinámicas de carácter global. El estudio de Paul Knepper muestra cómo el crimen se convirtió en un problema de la agenda internacional que había adquirido dimensiones globales desde fines del siglo XIX. ${ }^{69} \mathrm{La}$ construcción del campo de la policía científica trajo consigo la emergencia de una red de cooperaciones, conectando figuras directivas y departamentos policiales cuyo propósito era controlar el fenómeno de la criminalidad moderna. La dimensión global señalada aquí se debe menos a una extensión planetaria del campo -supuestamente presente en todos los Estados nacionales del mundo- y más al carácter internacional de la dinámica que la forjó. Frente a las formas de delincuencia que azotaron a las metrópolis modernas y la consolidación del capitalismo financiero a escala global, el internacionalismo fue visto como una respuesta y una clave analítica para comprender dicho fenómeno, siendo capaz de orientar las acciones policiales para controlar las prácticas criminales y preservar el orden político-económico capitalista liberal de principios del siglo $\mathrm{xx}$.

CONSIDERACIONES FINALES

Al final del siglo xix, la inserción de la economía brasileña en el capitalismo financiero internacional resultó en el desarrollo de prácticas delictivas de especulación y falsificación de papel moneda, así como de diferentes tipos de documentos fiduciarios. Junto con la promoción de incendios criminales como estrategia

${ }^{69}$ Knepper, The Invention of International Crime, p. 2. 
de obtención de los valores correspondientes a las pólizas de seguro, estas prácticas delictivas evidenciaron que el proceso global de consolidación del sistema capitalista financiero no se resumía a un fenómeno lineal, sino que había estado impregnado de grietas y percances que golpearon los bancos y las aseguradoras que actuaban en los Estados nacionales sudamericanos y europeos. Tales episodios resultaron en esfuerzos de cooperación entre las fuerzas policiales de ambos continentes que veían el internacionalismo como respuesta para la lucha de prácticas delictivas que atentaban tanto contra la propiedad privada individual, como contra el patrimonio de instituciones que movilizaban capitales procedentes de los grandes centros económicos internacionales.

Por medio de las visitas de los criminalistas, traducciones de textos e intercambio de correspondencias entre personalidades internacionales, Elysio de Carvalho favoreció la circulación de un conjunto de saberes de la policía científica que tenían como fin, primero, reprimir las prácticas criminales que colocaban en riesgo la propiedad privada de los ciudadanos, así como el capital económico de las instituciones bancarias y de las compañías de seguros. Al demostrar la importancia de los saberes de la policía científica frente a tales instituciones internacionales, el Gabinete de Identificación de Río de Janeiro buscaba solucionar las asimetrías y disputas que impregnaron las secciones policiales de la capital federal brasileña. Frente a los esfuerzos de modernización de la institución policiaca carioca que ocurrieron desde finales del siglo xix, Elysio de Carvalho necesitaba proyectar el Gabinete de Identificación como una sección capaz de controlar el fenómeno de la criminalidad moderna a partir del proyecto de una policía científica. De esta forma, en este juego de escala que involucró la actuación de un individuo, el Gabinete de Identificación y Estadística de Río de Janeiro y los laboratorios de la policía científica internacionales constituyeron el objeto de estudio de este trabajo. 


\section{SIGLAS Y REFERENCIAS}

BNB Biblioteca Nacional del Brasil, Brasil.

BNF Bibliothèque Nationale de France, Francia.

Artières, Philippe, La police de l'écriture: l'invention de la déliquance graphique (1852-1945), París, La Décourverte, 2013.

Bunker, Steven B., "El robo-homicidio de la joyería 'La Profesa': un crimen transnacional”, en Trujillo Bretón (coord.), 2010, pp. 405-425.

Caimari, Lila y Máximo Sozzo, Historia de la cuestión criminal en América Latina, Rosario, Prohistoria, 2017.

Carvalho, Elysio de, A luta técnica contra o crime, Río de Janeiro, Imprensa Nacional, 1914.

Carvalho, Elysio de, L'organisation et le fonctionnement du Service d'Identification de Río de Janeiro, Río de Janeiro, Imprensa Nacional, 1914.

Carvalho, Elysio de, "A nossa moeda papel não possui elementos de defesa contra a falsificação”, en Boletim Policial, viII: 3 (mar. 1914), pp. 107-109.

Carvalho, Elysio de, "Delinquência dos estrangeiros", en Boletim Policial, vII: 7 (jul. 1913), pp. 217-222.

Carvalho, Elysio de, "História Natural dos Malfeitores: Notas e crônicas", en Boletim Policial, vII: 4 (abr. 1913), p. 61.

Carvalho, Elysio de, “A indústria dos incêndios criminosos”, en Boletim Policial, viI: 12 (abr. 1913), pp. 469-472.

Carvalho, Elysio de, "Relatório do Diretor do Gabinete de Identificação e de Estatística, correspondente ao ano de 1912, apresentado ao Ex. Sr. Chefe de Polícia do Distrito Federal”, en Boletim Policial, vir: 1-3 (ene.-mar. 1913), pp. 21-25.

Carvalho, Elysio de, “A falsificação dos nossos valores circulantes”, Boletim Policial, v: 18-20 (oct.-dic. 1911), pp. 591-604.

Carvalho, Elysio de, “O mundo dos criminosos III”, en Ilustração Brasileira (16 dic. 1910), pp. 202-203. 
“Exposição Internacional e Urbana de Lyon”, en Boletim Policial, viI: 7 (jul. 1913), pp. 258-259.

Fausto, Boris, História do Brasil, São Paulo, Editora da usp, 1994.

Fausto, Boris (ed.), Fazer a América: a imigração em massa para a América Latina, São Paulo, Edusp, 2000.

Galeano, Diego Antonio, "Criminosos, viajantes, vigilantes modernos: circulações policiais entre Río de Janeiro e Buenos Aires, 1890-1930", Río de Janeiro, tesis de doctorado, Universidade Federal do Rio de Janeiro, 2012.

Galeano, Diego Antonio, "Historia da moeda falsa no mundo atlântico: itinerário de pesquisa”, en Vendrame, Mauch y Moreiras (eds.), 2018, pp. 67-99.

Galeano, Diego Antonio, "Un artista del delito: circulación de dinero falso entre el Río de la Plata y el Brasil 1899-1911”, en CaImari y Sozzo, 2017, pp. 195-233.

Ginzburg, Carlo, Mitos, emblemas, sinais: morfologia e história, São Paulo, Companhia das Letras, 1990.

Gonçalves, Gonçalo Rocha, “'A foice de dez reis' e 'a febre dos seguros’: protesto social e a comodificação da insegurança em Portugal (1910-1926)”, mimeo, 2019.

Gónzalez GónZalez, Enrique, "Un espía en la universidad. Sancho Sánchez de Muñón, Maestrescuela de México. (1560-1600)”, en Menegus (coord.), 1997, pp. 105-170.

Júnıor, Caio Prado, História Econômica do Brasil, São Paulo, Editôra Brasilense, 1965.

Kalifa, Dominique. Os bas-fonds: história de um imaginário, São Paulo, Edusp, 2017.

Knepper, Paul, The Invention of International Crime: A Global Issue in the Making, 1881-1914, Londres, Palgrave Macmillan, 2010.

LOCARD, Edmond, "Laboratórios de polícia e instrução criminal”, Boletim Policial, vII: 5 (may. 1913), pp. 89-105. 
Locard, Edmond, "Perícia Gráfica”, Boletim Policial, año vi: 10-12 (oct.-dic. 1912), pp. 304-311.

Martins, Marcelo Thadeu Quintanilha, “A civilizaçao do Delegado: Modernidade, polícia e sociedade em São Paulo nas primeiras décadas da República, 1889-1930", tesis de doctorado en Historia Social, Universidade de São Paulo, 2012.

Menegus, Margarita (coord.), Saber y poder en México. Siglos XVI al XX, México, Universidad Nacional Autónoma de México, 1997.

Mıнм, Stephen, A Nation of Counterfeiters: Capitalists, Con Men, and the Making of the United States, Cambridge, Havard University Press, 2019.

“Notícias policiais”, en Boletim Policial, v: 18-20 (ago.-dic. 1911), p. 667.

Quinche, Nicolas, Sur les traces $d u$ crime. De la naissance $d u$ regard indicial à l'institutionnalisation de la police scientifique et technique en Suisse et en France, Ginebra, Slatkine, 2011.

Quinche, Nicolas, Crime, science et identité: Anthologie des textes fondateurs de la criminalistique européenne (1860-1930), Ginebra, Slatkine, 2006.

ReIss, Rudolphe A., Polícia Técnica. Resumo das conferências realizadas em S. Paulo, Río de Janeiro, Imprensa Nacional, 1914.

ReIss, Rudolphe A., O resumo das conferências realizadas no Rio, Río de Janeiro, Imprensa Nacional, 1914.

Reiss, Rudolphe A., "Os métodos científicos nos inquéritos judiciários e policiais”, en Boletim Policial, r: 1 (may. 1907), p. 16.

Rouillé, André, A fotografia entre documento e arte contemporânea, São Paulo, Editora Senac São Paulo, 2009.

Roussoulières, Leon, “A falsificação de valores fiduciários”, en Boletim Policial, viII: 8-12 (ago.- dic. 1914), pp. 348-350.

SANT'ANA, Moacir Medeiros de, Elysio de Carvalho, um militante do anarquismo, Maceió, Arquivo Público de Alagoas, 1982. 
SiLva, Henry Marcelo Martins, "Nos trilhos do capital: 'engenheiros industriais' e ferrovias em São Paulo no início do século xx”, en História, 22: 4 (201), pp. 551-565.

Trujillo Bretón, Jorge Alberto (coord.), En la encrucijada. Historia, marginalidad y delito en América Latina y los Estados Unidos de Norteamérica (siglos XIX Y XX), Guadalajara, Universidad de Guadalajara, 2010.

Vendrame, Maíra Ines, Cláudia Mauch y Paulo Robertos Moreira (eds.), Crime e Justiça: Reflexões, fontes e possibilidades de pesquisa, São Leopoldo, Unisinos, 2018. 
